\title{
Lung volume reduction surgery
}

\author{
Duncan M Geddes
}

Royal Brompton Hospital, Sydney Street, London, UK

Introductory articles

Relation between preoperative inspiratory lung resistance and the outcome of lung volume reduction surgery for emphysema

\author{
E P Ingenito, R B Evans, S H Loring, D W Kaczka, J D Rodenhouse, S C Body, D J Sugarbaker, \\ S J Mentzer, M M DeCamp, J J Reilly Jr
}

Background. Surgery to reduce lung volume has recently been reintroduced to alleviate dyspnea and improve exercise tolerance in selected patients with emphysema. A reliable means of identifying patients 9 who are likely to benefit from this surgery is needed. Methods. We measured lung resistance during $\vec{\longrightarrow}$ inspiration, static recoil pressure at total lung capacity, static lung compliance, expiratory flow rates, 0 and lung volumes in 29 patients with chronic obstructive lung disease before lung-volume-reduction surgery. The changes in the forced expiratory volume in one second (FEV $)$ six months after surgery $\overrightarrow{0}$ were related to the preoperatively determined physiologic measures. A response to surgery was defined $₫$ as an increase in the FEV ${ }_{1}$ of at least 0.2 liter and of at least 12 percent above base-line values. Results. Of the 29 patients, 23 had some improvement in FEV 1 including 15 who met the criteria for a response to surgery. Among the variables considered, only preoperative lung resistance during inspiration predicted changes in expiratory flow rates after surgery. Inspiratory lung resistance correlated significantly and inversely with improvement in FEV ${ }_{1}$ after surgery $(r=-0.63, P<0.001)$. A preoperative criterion of an inspiratory resistance of $10 \mathrm{~cm}$ of water per liter per second had a sensitivity of $88 \stackrel{\Xi}{\Xi}$ percent (14 of 16 patients) and a specificity of 92 percent (12 of 13 patients) in identifying patients who were likely to have a response to surgery. Conclusions. Preoperative lung resistance during inspiration appears to be a useful measure for selecting patients with emphysema for lung volumereduction surgery (N Engl J Med 1998;338:1181-5)

\section{Two year results after lung volume reduction surgery in $\alpha_{1}$-antitrypsin deficiency versus smoker's emphysema}

P C Cassina, H Teschler, N Konietzko, D Theegarten, G Stamatis

Lung volume reduction surgery (LVRS) improves exercise capacity and relieves dyspnoea in patients with 0 smoker's emphysema (SE). It is unclear, however, whether LVRS similarly improves lung function in $\alpha_{1}-\mathrm{N}$ antitrypsin-deficiency emphysema $(\alpha, E)$. To address this question, this study prospectively compared the $N$ intermediate-term functional outcome in 12 consecutive patients with advanced $\alpha_{1} E$ and 18 patients ${ }_{2}$ with SE who underwent bilateral LVRS. Before surgery there were no statistically significant differences $\stackrel{\bullet}{=}$ between the two groups in the six-minute walking distance, dyspnoea score, respiratory mechanics or $\stackrel{\mathbb{2}}{?}$ lung function data, except for the forced expiratory volume in one second, which was lower in the deficient group (24 versus $31 \%$ of the predicted value; $p<0.05$ ). In both groups, bilateral LVRS produced $\stackrel{\overrightarrow{\mathbb{D}}}{\mathrm{D}}$ significant improvements in dyspnoea, the six-minute walking distance, lung function and respiratory $\frac{\stackrel{\rho}{\mathbb{D}}}{\mathrm{D}}$

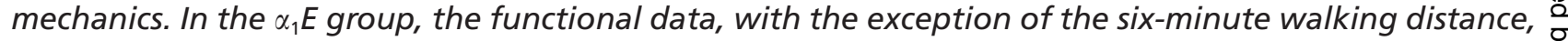
returned to baseline at 6-12 months postoperation and showed further deterioration at 24 months. The functional status of the SE group remained significantly improved over this period. In conclusion, 8 the functional improvements resulting from bilateral lung volume reduction surgery are sustained for $\overline{\overline{0}}$. at least 2 yrs in most patients with smoker's emphysema, but this type of surgery offers only short- $\frac{\vec{\sigma}}{?}$ term benefits for most patients with $\alpha_{1} E$. (Eur Respir J 1998;12:1028-32) 
The explosion in interest in lung volume reduction surgery (LVRS) is well demonstrated by the number of operations being carried gut and the number of publications claiming benefit ${ }^{1}$ This traditional way of accumulating and sharing surgical experience is valuable but inevitably provides distorted evidence. In the first place there is unavoidable publication bias; poor results and high mortality are unlikely to be written up and unlikely to be published. Secondly, all series of operations are performed on highly selected patients with individual surgeons using personal selection criteria which may differ between centres. In particular, the likely inclusion of patients with classical bullae in some series may greatly overvalue the benefits of the operation. The results are therefore difficult to compare and impossible to apply to wider groups of patients. Thirdly, there are no controlled studies and so evaluation of long term results against the expected long term decline in unoperated patients involves imagination and guesswork.

Against this background all reports of selection criteria and long term results are welcome but must be evaluated cautiously. The two studies by Ingenito et a ${ }^{2}$ and Cassina et $d l$ are good examples.

Ingenito et $d l^{2}$ propose that a low inspiratory lung resistance (ILR) may help to select suitable patients for surgery. The logic behind the hypothesis is good and, while their results are supportive, there are a number of caveats. Firstly, the observation must be repeated in a prospective way. Multiple linear regression analysis is good at finding correlations within a particular series but often the finding cannot be confirmed in another group. Secondly, hidden selection criteria before entry into the study may be very important. Although the patients in this study were chosen in the usual way from ex-smokers with emphysema and flattened diaphragms, this still leaves plenty of room for physician judgement of suitability according to clinical, lung function, and computed tomographic (CT) findings. Most centres find that they exclude up to $80 \%$ of referrals so the value of ILR or any other test may apply only to a subset of $20 \%$. Thirdly, there are some technical curiosities in the data: static compliance of $0.25 \mathrm{l} / \mathrm{cm} \mathrm{H}_{2} \mathrm{O}$ is low for severe emphysema but was measured over the range total lung capacity (TLC) -0.51 to TLC. Similarly, the control ILR of $1.0 \mathrm{~cm} \mathrm{H} \mathrm{H}_{2} \mathrm{O} / \mathrm{l} / \mathrm{s}$ is rather low. While these points do not invalidate the conclusions, they emphasise the difficulties involved in processing oesophageal measurements. Finally, ILR is derived from four separate variables, each with technical problems, and few laboratories are familiar with oesophageal pressure measurements and their artefacts (heart beat, oesophageal contractions, etc). While these problems are not insurmountable, they certainly limit easy and early adoption of this measurement as a selection criterion for LVRS. Further confirmatory studies are needed before everybody jumps onto this band wagon.

Compared with smoker's emphysema (SE), $\alpha_{1}$-antitrypsin deficiency emphysema $\left(\alpha_{1} \mathrm{E}\right)$ is more widespread and severe, progresses more rapidly, and is worse in the lower lobes. As a result LVRS may be technically more difficult to perform with a higher complication rate and the benefits may be smaller and briefer. Because $\alpha_{1} \mathrm{E}$ is rare and because some early reports suggested better results in upper zone disease, relatively few patients with $\alpha_{1} E$ have had LVRS and the evidence is limited One study suggested the outcome for $\alpha_{1} \mathrm{E}$ was poor while others have either excluded $\alpha_{1} \mathrm{H}^{5}$ or have not analysed such patients separately Nevertheless, the role of LVRS in $\alpha_{1} \mathrm{E}$ is particularly important to define since these patients present with the worst symptoms at a relatively young age.

The report by Cassina et a is at first sight encouraging with similar three month benefits for $\alpha_{1} E$ and SE and therefore argues against the usual advice that those $\frac{0}{2}$ with lower zone emphysema do worse. The difference ? between the two groups in the durability of benefit is $\vec{F}$ perhaps less striking than the abstract implies. Certainly $\frac{\text { ? }}{9}$ forced expiratory volume in one second $\left(\mathrm{FEV}_{1}\right)$, total $\frac{\mathrm{C}}{\mathrm{O}}$ lung capacity (TLC), and residual volume (RV) declined $\overline{\bar{\omega}}$ faster in the $\alpha_{1} \mathrm{E}$ group from three to 12 months but thereafter the slopes were parallel. In contrast, the decline in dyspnoea score, six minute walking distance, and क diaphragmatic pressure were similar for both groups. $\vec{\circ}$ Furthermore, patients with $\alpha_{1} \mathrm{E}$ lose $\mathrm{FEV}_{1}$ and lung $\vec{\overrightarrow{ }}$ volumes more rapidly even without LVRS and so the of reported decline cannot be attributed to the operation alone. Clearly, any statement about long term decline would be strengthened by the inclusion of an unoperated control group.

Taken together these reports make a valuable con- $\infty$ tribution to the LVRS debate, but also emphasise the problems of building an evidence base on highly selected $\vec{f}$ patients without controls. So where is LVRS now? Patients want it and surgeons want to do it, while still $\vec{\nabla}$ debating the best operative technique. In contrast public $\widetilde{\emptyset}$ health advisers, those who hold the purse strings and, $\frac{\mathfrak{c}}{2}$ to a lesser extent, physicians are still asking the following questions:

- Does LVRS really work?

- If it works, how, who and when?

- Is it worth it?

\section{Does LVRS really work?}

The review by Russi et al in 19978 listed 10 reports on a total of 958 patients who had had LVRS. Improvements in $\mathrm{FEV}_{1}$ ranged from $13 \%$ (VATS with laser) to an astonishing $82 \%$. Since then there have been at least 16 more reports on over 800 further patients (the exact number is unclear due to duplicate reporting) with similar changes. The reported changes following LVRS are summarised in table 1.

Most series have included preoperative rehabilitation $\dot{\delta}$ which achieved some improvement in exercise tolerance but have shown further increase in walking distance 을 after LVRS, usually in line with improvement in $\mathrm{FEV}_{1}$. When measured, quality of life usually shows parallel 을 improvements. These benefits are best at 3-6 months and the few studies which have included longer term measurements show either "sustained benefit at 1-2

\begin{tabular}{|c|c|}
\hline Spirometry & $\mathrm{FEV}_{1}$, flow rates, VC $\uparrow$ \\
\hline Plethysmography & $\begin{array}{l}\text { RV, TLC } \downarrow \\
\text { Airway resistance } \downarrow \\
\text { Specific conductance } \uparrow\end{array}$ \\
\hline Diffusion & TLCo $\uparrow$, Kco unchanged \\
\hline Blood gases & $\mathrm{PaO}_{2} \uparrow /-, \mathrm{PacO}_{2} \downarrow /-$ \\
\hline Exercise & $\begin{array}{l}\text { Walking distance } \uparrow \\
\text { Vo }_{2} \max , \operatorname{VEmax} \uparrow\end{array}$ \\
\hline Subjective & $\begin{array}{l}\text { Dyspnoea } \downarrow \\
\text { Quality of life } \uparrow\end{array}$ \\
\hline
\end{tabular}

$\mathrm{FEV}_{1}=$ forced expiratory volume in one second; $\mathrm{VC}=$ vital capacity $\mathrm{RV}=$ residual volume; $\mathrm{TLC}=$ total lung capacity; $\mathrm{TLCO}=$ carbon mon oxide transfer factor; $\mathrm{KCO}=$ transfer coefficient: $\mathrm{PaO}_{2} \mathrm{PacO}_{2}$ arterial oxygen and carbon monoxide tensions: $\mathrm{VO}$ max $=$ maximum oxygen uptake; $V_{E m a x}=$ maximum minute ventilation. 
years" or subsequent decline. There are not enough long term data to give a clear picture of what happens after two years. In any event, such long term data would be difficult to judge without untreated controls. Deaths, operative complications, and longer term disadvantages are only inconsistently reported_Operative/short term mortality ranges from 0 to $17 \%$ with one study reporting death in six of 16 patients in a subgroup with a combination of $\mathrm{PaCO}_{2}>45 \mathrm{~mm} \mathrm{Hg}(6.2 \mathrm{~Pa})$ and six minute walking distance less than $200 \mathrm{~m}^{11}$ There are a few reports of surgical units having bad results, particularly in the first few operations, and it is very likely that selective reporting gives a falsely good picture. Inevitably, centres with greater experience become increasingly skilled at patient selection and perioperative management, and mortality probably settles at around $5 \%$. In this context it is salutary to remember that Brantigan's original operation in the 1950 s never caught on because of an early mortality of around $16 \%$.

There is therefore a large body of evidence reporting benefit but, in spite of this, not everyone is convinced. Medicare has refused to fund LVRS in the absence of a controlled clinical trial and the American Thoracic Society, among many other groups, has also called for better evidence. ${ }^{13}$ Such controlled trials have been started and one UK trial will shortly be reported. Unfortunately they are notoriously difficult to conduct since determined patients may shop around and many are reluctant to spend their declining years in an untreated control group while reading newspaper reports of dramatic benefits. This is especially a problem in a mixed health care system where money talks and surgeons are already convinced that the operation works. Patients allocated to the control arm are likely to pay for an operation privately.

Meanwhile some surgeons remain unconvinced of the need for a controlled trial and consider the size and statistical significance of the changes after surgery as sufficient proof. Furthermore, Myers et al have compared 22 LVRS candidates denied surgery by Medicare with 65 "contemporaneous and comparable" LVRS recipients. ${ }^{14}$ The surgical group showed sustained improvement and $82 \%$ survival while those denied surgery lost lung function and had $64 \%$ survival.

So, does it really work? Of course it does, but only for the right person at the right time in the right place. Perhaps if we know how it works we will be better at answering the questions who and when.

\section{How does LVRS work?}

In emphysema destruction and distension of alveoli lead to a loss of elastic recoil which itself results in a lower driving pressure for expiration and a reduction in radial traction on airways. Early airway closure causes hyperinflation with intrinsic positive end expiratory pressure (iPEEP) and the respiratory muscles work at a mechanical disadvantage. The destruction and hyperinflation are patchy with compression of healthy lung, distortion of airways, and impaired matching of ventilation and perfusion. Furthermore, smoking does not cause pure emphysema and some degree of intrinsic airway narrowing co-exists. While all these changes contribute to breathlessness, respiratory muscle dysfunction is particularly important. In the first place a short flat diaphragm generates less pressure; secondly, a change in the shape of the rib cage with less apposition of the diaphragm together with altered orientation of muscle fibres is mechanically inefficient; and finally, the relative contribution of the diaphragm and other respiratory muscles is deranged and incoordinate.

All of these changes, with the exception of intrinsic airway narrowing, are potentially corrected by LVRS and measures of each have been reported to improve. In particular, the static elastic recoil pressure increases with favourable effects on driving pressure, airway trac- $\vec{F}$ tion, and therefore expiratory flow rates. Volume re- $\frac{\text { ? }}{9}$ duction moves ventilation to a more optimal part of the pressure/volume curve and a reduction in intrinsic PEEP $\frac{\bar{\sigma}}{\bar{\omega}}$ increases dynamic compliance. In addition, recruitment $\underset{\mathbb{\Phi}}{\overparen{D}}$ of healthy lung units and correction of distorted airway geometry may also contribute. The above changes in rib cage shape and respiratory muscle function are all $\overrightarrow{0}$ to some degree reversed with consequent increase in diaphragmatic pressures and better coordination of the diaphragm and other respiratory muscles.

There have also been some reported improvements in gas exchange with reduction in dead space ventilation, in haemodynamics with improvements in right vent- 0 ricular function and exercise pulmonary vascular re- $\infty$ sistance, and in measures of respiratory drive. All these $\rightarrow$ changes are somewhat inconsistent and likely to be less important than the changes in lung mechanics and muscle function. The net effect of these improvements $\vec{\nabla}$ is better exercise performance which is chiefly reflected $\mathbb{0}$ in an increase in tidal volume and ventilatory reserve $\stackrel{5}{\omega}$ with a reduction in dead space/tidal volume ratio. The consequent reduction in work of breathing, both at 6 rest and on exercise, then reduces the sensation of breathlessness with favourable effects on exercise performance and quality of life.

While all these mechanisms are to some extent confounded by secondary adaptations and the relevant measurements are subject to artefact leading to the sort $\stackrel{\square}{2}$ of debate that is enjoyed by respiratory physiologists, the $\overrightarrow{\overrightarrow{0}}$ overall messages are clear. Firstly, the most important effects of LVRS are on elastic recoil and respiratory muscle function. Secondly, there is a complex interaction of effects such that non-responders to surgery show the same preoperative functional changes as responders. Thirdly, no single preoperative measure is yet $\stackrel{x}{\sigma}$ accepted as a good preoperative predictor of benefit. 3 . The report on ILR by Ingenito et alp should be seen in this context, but we are still far from defining precisely who will benefit from surgery and when to do it.

\section{LVRS: who and when?}

Most groups have selected or excluded patients ac- o cording to the criteria in table 2 . These are clinically

\begin{tabular}{|c|c|}
\hline Inclusion & Exclusion \\
\hline $\begin{array}{l}\text { Severe airflow obstruction } \\
\left(? \mathrm{FEV}_{1}<35 \%\right)\end{array}$ & Continued smoking \\
\hline $\begin{array}{l}\text { Predominant emphysema } \\
\text { (?TLCO }<60 \%)\end{array}$ & ?TLCO <20\% \\
\hline Little reversibility $(<15 \%)$ & Regular prednisolone ?>15 mg daily \\
\hline $\begin{array}{l}\text { Pulmonary hyperinflation } \\
(? \mathrm{RV}>180 \%)\end{array}$ & $\begin{array}{l}\text { Other significant lung disease, e.g. } \\
\text { infection, bronchiectasis, neoplasia }\end{array}$ \\
\hline $\begin{array}{l}\text { CT changes: heterogeneous, } \\
\text { upper zone predominant } \\
\text { emphysema }\end{array}$ & $\begin{array}{l}\text { Coronary artery disease/poor } \\
\text { cardiac function }\end{array}$ \\
\hline Functional impairment & Serious systematic disease \\
\hline Reduced quality of life & \\
\hline
\end{tabular}

EV $\mathrm{f}_{1}$ forced expiratory volume in one second; TLCO = carbon monoxide transfer factor; $\mathrm{RV}=$ residual volume. 
sensible selection criteria intended to minimise risk and maximise the chances of benefit but none has been formally tested. LVRS centres have turned down 50$80 \%$ of early referrals reflecting, on the one hand, relative lack of experience among referrers and, on the other, desperation and willingness to clutch at straws among patients with high levels of symptoms. In spite of this selection, mortality still ranges from $4 \%$ to $17 \% .1 \%$ Operative risk is naturally higher when experience is limited and the severity of the underlying disease is worse. Szekely et a p $^{11}$ reported unacceptable mortality with low walking distance and high $\mathrm{PaCO}_{2}$, and our own experience would confirm this together with an increased risk with low carbon monoxide transfer factor (TLCO). In contrast, Eugene et al reported good outcomes among 41 patients with $\mathrm{FEV}_{1}<500 \mathrm{ml}, 80 \%$ of whom were oxygen dependent and hypercapnic. ${ }^{15}$ This suggests that with increasing experience the risk falls even among the most severely affected patients. At present there is insufficient evidence to give clear cut exclusion criteria based on lung function measurements or mobility.

Only $50-75 \%$ of patients improve with surgery so reliable predictors of benefit are badly needed. Clearly, the more patchy the disease the easier it is for the surgeon to select target areas for volume reduction and the greater the chance of reclaiming function from surrounding compressed lung. The extreme example of this is the large isolated bulla and bullectomy has been well established as an effective treatment for many years, particularly when there is evidence of compressed lung on CT scanning together with good lung function elsewhere Zonal distribution is similarly important and the Zuric ${ }^{16}$ and St Loui ${ }^{17}$ groups have shown better results with upper than with lower zone predominant emphysema, although this finding may be confounded by the greater heterogeneity and better function of the remaining lung that tends to go with upper zone predominance. There is now reasonable evidence that CT scanning is as good as any other imaging technique in assessing heterogeneity and distribution and neither ventilation/perfusion scanning nor magnetic resonance imaging have shown any worthwhile advantages. In spite of these arguments there is accumulating evidence that homogeneous disease without any obvious target areas for resection can also improve with volume reduction and it is in this group that preoperative functional measurement predicting success is likely to be the most valuable. If the main mechanisms involved are alteration in elastic recoil and diaphragmatic configuration, it is logical to propose that preoperative assessment should focus on simple associated variables such as diaphragmatic shape and pressure generation. All centres carrying out LVRS should be encouraged to perform full functional assessments before surgery and to continue to search for correlations with success and failure.

Although there has been much discussion and many 걱 publications about selection criteria in terms of severity $\frac{0}{2}$ and distribution of emphysema, little attention has been $\stackrel{x}{x}$ focused on timing. Lung function deteriorates with age $\underset{\vec{\rho}}{\vec{\rho}}$ in non-smokers and faster in smokers and the optimal $\frac{0}{9}$ moment for LVRS is unknown. Furthermore, operative 듬 risk inevitably increases with both age and deteriorating $\bar{\omega}$ lung function. If surgery is proposed relatively early the $\vec{\Phi}$ risks will be lower but there may not be enough to gain. Conversely, to wait until symptoms and disability are $\$$ severe may subject the patient to an unacceptable risk. $\vec{\circ}$ The decision is further complicated by the facts that $\vec{\overrightarrow{ }}$ lung function correlates poorly with symptoms and there is an interaction between personality and psychological $\overrightarrow{\vec{x}}$ state, on the one hand, and the level of symptoms for of a given functional impairment on the other. People with emphysema tend to become frustrated by their 8 immobility and depression and resentment can be a consequence. Such people shout the loudest for an $\vec{A}$ operation but are the ones who will be most damaged $\vec{A}$ by a poor result. Conversely, the stoic who copes well with disability may be an ideal candidate for surgery $\vec{D}$ but never comes forward because he doesn't complain enough. Smoking cessation, weight reduction, and pre- $\frac{5}{\oplus}$ operative rehabilitation are all valuable in improving the $\overrightarrow{\vec{\theta}}$ patient's mobility before a decision on surgery is taken. The delay also allows some estimate of the rate of decline of lung function. Improved weight and symptoms with no evidence of functional decline persuades many patients and their physicians to leave well alone. Finally, $\bar{o}$ no one knows whether LVRS is good or bad in the longer term. This is important for younger patients with dependants who want to know about the benefits and $\overrightarrow{\overline{0}}$ risks over 20 years. Clearly, we do not know all the answers and it will take a long time to find out. Everyone in the field has a responsibility to keep good records and ensure long term follow up so that we get the answers quickly.

\section{Is it worth it?}

There are two ways of looking at the cost/benefit ratioclinical and health economic. The clinical debate ranges 을 from enthusiasts recounting their best clinical anecdote to detractors remembering the deaths and prolonged morbidity in those who do not improve. The resolution $\overline{\mathrm{N}}$ of these arguments must lie in improved patient selection $\sigma$ so that non-responders are spared the operation and $\stackrel{N}{\circ}$ success rates increase. We must of course wait for the much longer term results before the clinical cost/benefit ${ }_{2}$

\section{LEARNING POINTS}

* LVRS is of benefit to some but not all patients.

* Patient selection is crucial but further refinement of the selection criteria is required.

* The timing of LVRS in the natural history of the disease is important.

* Current surgical series describe benefit from LVRS but controlled trials are required. These will be difficult to carry out.

* LVRS should be done in a small number of specialised centres with the necessary expertise, treating sufficient numbers of patients to answer outstanding questions regarding the technique. 
analysis is complete. The health economic arguments are more complex. LVRS is expensive and potential candidates are elderly and numerous. As a result funders are asking for health economic evaluation and better proof before signing any cheques. Hospital costs depend upon the length of stay and range in the USA from $\$ 11712$ to $\$ 121829.18$ Higher costs and longer stays tend to go with increasing age and it is worth remembering that, of the estimated 14 million people with chronic obstructive pulmonary disease in the USA, most are over 70 . These costs need to be balanced against the improved quality of life and the duration of the improvement, neither of which have yet been fully evaluated. Eventually it should be possible to compare the benefit in quality adjusted life years between LVRS and, for example, coronary artery bypass surgery or hip replacement. These analyses are clearly important but should not lead to premature conclusions before the details of the operation selection criteria have been worked out. LVRS has a similar potential for benefit to coronary artery bypass surgery and hip replacement but it is a relatively new arrival on the scene.

\section{Conclusions}

LVRS works and is here to stay. We do not have all the answers and the best way to get them is to have relatively few very active LVRS centres who keep good records and disseminate the results of their work. A proliferation of small units providing the operation would be counterproductive. Inevitably a number of the questions will take many years to answer and, in the meantime, we should be pleased that the evidence base is developing in a much more complete way than is the case for almost all other major operations. We should not allow the incompleteness of this evidence base and the cost of surgery to deny patients benefit. For many hundreds of thousands of people with emphysema LVRS could make as much difference to them as coronary artery surgery does for those with ischaemic heart disease. The two operations have a similar evidence base and should be given similar priority.

1 Russi E, Weder W. Lung volume reduction surgery. Eur Respir f 1999; 13:480.

2 Ingenito EP, Evans RB, Loring SH, et al. Relation between preoperative inspiratory lung resistance and the outcome of lung volume reduction surgery for emphysema. N Engl f Med 1998;338:1181-5.

3 Cassina PC, Teschler H, Konietzko N, et al. Two year results after lung volume reduction surgery in $\alpha_{1}$-antitrypsin deficiency versus smoker's emphysema. Eur Respir f 1991;12:1028-32.

4 Bavaria JE, Pochettino A, Kotloff RM, et al. Effect of volume reduction on lung transplant timing and selection for chronic obstructive pul- ڤ્心

monary disease. $\mathcal{F}$ Thorac Cardiovasc Surg 1998;115:9-17.
5 McKenna RJ, Brenner M, Gelb AF, et al. A randomised prospective $\overrightarrow{0}$ trial of stapled lung reduction versus laser bullectomy for diffuse emphysema. F Thorac Cardiovasc Surg 1996;111:317-22.

6 Cooper JD, Trulock EP, Triantafillou AN, et al. Bilateral pneumonectomy (volume reduction) for chronic obstructive pulmonary disease. f Thorac Cardiovasc Surg 1995;109:106-19.

7 Teschler H, Stamatis G, el-Raouf Farhat AA, et al. Effect of surgical lung volume reduction on respiratory muscle function in pulmonary emphysema. Eur Respir f 1996;9:1779-84.

8 Russi EW, Stammberger U, Weder W. Lung volume reduction surgery for emphysema. Eur Respir f 1997;10:208-18.

9 Marchand E, Gayan-Ramirez G, De Leya P, et al. Physiological basis of improvement after lung volume reduction surgery for severe emphysema: where are we? Eur Respir f 1999;13:686-96. 10 Sciurba FC. Early and long term functional outcomes following lung

11 Szekely LA, Oelberg DA, Wright C, et al. Preoperative predictors of operative morbidity and mortality in COPD patients undergoing bilateral lung volume reduction surgery. Chest 1997;111:550-8.

12 Fein AM, Branman SS, Casaburi R, et al. Lung volume reduction surgery. Am $\mathcal{F}$ Respir Crit Care Med 1996;110:885-8.

13 Fein AM. Lung volume reduction surgery: answering the crucial questions. Chest 1998;113(4 Suppl):277-82S.

14 Meyers BF, Yusen RD, Lefrak S, et al. Outcome of Medicare patients with emphysema selected for, but denied, a lung volume reduction operation. Ann Thorac Surg 1998;66:331-6.

15 Eugene J, Dajee A, Kayaleh R, et al. Reduction pneumenoplasty for patients with a forced expiratory volume in 1 second of $500 \mathrm{ml}$ or less. Ann Thorac Surg 1997;63:186-90.

16 Bingisser R, Zollinger A, Hauser M, et al. Bilateral volume reduction surgery for diffuse pulmonary emphysema by video assisted thoracoscopy. F Thorac Cardiovasc Surg 1996;112:875-82.

17 Slone RM, Pilgram TK, Gierada DS, et al. Lung volume reduction surgery: a comparison of preoperative radiologic features and clinical outcome. Radiology 1997;204:613-5.

18 Elpern EH, Behner KG, Klontz B, et al. Lung volume reduction surgery: an analysis of hospital costs. Chest 1998;113:896-9. 